Jurnal Ilmu Hukum

FAKULTAS HUKUM UMSU
Donor Anggota Tubuh...(Rasta Kurniawati Br. Pinem ) Volume 5 Nomor 1, Januari - Juni 2020, 67-78 DOI: https://doi.org/10.30596/dll.v5i1.3449

\title{
DONOR ANGGOTA TUBUH (TRANSPLANTASI) \\ MENURUT HUKUM ISLAM \\ (Upaya Mengidentifikasi Masalah dan Mencari Dalil-Dalilnya)
}

\author{
Rasta Kurniawati Br.Pinem \\ Fakultas Hukum Universitas Muhammadiyah Sumatera Utara \\ Jl. Kapten Mukhtar Basri No. 3, Medan - Sumatera Utara, Indonesia \\ Telp: (061) 6622400, Fax: (061) 6623474, 6631003), Kode Pos 20238 \\ Email : $\underline{\text { rastakurniawati@ umsu.ac.id }}$
}

\begin{abstract}
ABSTRAK
Antara kebutuhan yang mendesak secara kesehatan atau menjalankan ibadah, donor organ tubuh manusia menjadi permasalahan ketika banyak pendapat yang menyebutkan bahwa tindakan tersebut haram dilakukan karena didasari dari keraguan yang tidak pernah dicontohkan oleh Nabi Muhammad SAW. Namun di luar kedua alasan tersebut Islam tidak dapat menolak perkembangan atas adanya donor organ tubuh manusia yang saat ini sudah banyak dilakukan. Tulisan ini mengangkat satu permasalahan saja yaitu tindakan untuk melakukan donor organ tubuh manusia (transplantasi) dapat diperbolehkan atau tidak dalam Islam. Jenis penelitian yang digunakan dalam tulisan ini adalah penelitian pustakan dimana sumber data utama yang digunakan adalah Al-quran, al-hadist serta beberapa peraturan yang ada di Indonesia. Sumber data yang lain adalah seperti sumber data sekunder dan tertier. Adapun hasil dari penelitian ini adalah organ tubuh diperbolehkan apabila organ tubuh tersebut itu miliknya sendiri, karena meskipun tubuh merupakan titipan dari Allah, manusia diberi wewenang untuk memanfaatkannya dengan mempergunakanya, sebagai harta. Maka Allah SWT. memberi wewenang kepada manusia untuk memilikinya dan membelanjakan harta itu. Sebagaimana manusia boleh mendermakan sebagian hartanya untuk kemaslahatan orang lain yang membutuhkannya maka diperkenankan juga seseorang mendonorkan sebagian tubuhnya untuk orang lain yang memerlukannya.
\end{abstract}

\section{Kata Kunci: Tranplantasi, Hukum Islam, Tubuh Manusia.}

\section{ABSTRACT}

Between the urgent need for health or worship, the donor of human organs becomes a problem when many opinions say that the act is haram because based on doubts that were never exemplified by the Prophet Muhammad. But apart from these two reasons Islam cannot refuse the development of human organ donation which is currently being done. This paper aims one problem, namely the act of donating human organs (transplants) can be allowed or not in Islam. This type of research used in this writing is library research in which the main data sources used are the Qur'an, al-hadith and some regulations in Indonesia. Other data sources are like secondary and tertiary data sources. The result of this research is that the organs of the body are allowed if they are their own, because even though the body is entrusted by God, humans are given the authority to use it, as a treasure. Then Allah SWT authorizes humans to own it and spend the treasure. Just as a human being can give away part of his wealth to benefit others who need it, it is also permissible for someone to donate part of his body to others who need it.

Keywords: Transplantation, Islamic Law, Human Body. 
DE LEGA LATA

Jurnal Ilmu Hukum

FAKULTAS HUKUM UMSU
Donor Anggota Tubuh...(Rasta Kurniawati Br. Pinem ) Volume 5 Nomor 1, Januari - Juni 2020, 67-78 DOI: https://doi.org/10.30596/dll.v5i1.3449

\section{PENDAHULUAN}

Perkembangan zaman tidak dapat dibendung dengan berbagai alasan, karena secara prinsipnya manusia membutuhkan perubahan atas adanya tuntutan kebutuhan. Tuntutan atas kebutuhan ini secara lahiriah karena adanya perubahan kebutuhan manusia yang selalu berubah setiap waktunya, setiap zaman pasti adanya kebutuhan baru yang diinginkan manusia.

Perkembangan zaman yang seolah-olah menuntut setiap manusia untuk selalu bertahan mengakibatkan bagaimana pemikiran akan ide-ide baru dalam hal pemenuhan kebutuhan manusia demi bertahan hidup, mulai dari memenuhi sandang dan pangan hingga kebutuhan mendasar seperti bertahan dari penyakit. Tidak ada akan yang mengira bahwa organ tubuh manusia dapat dipindahkan tubuh manusia yang satu ke tubuh manusia yang lain, karena pada awalnya manusia memang tidak sanggup untuk melakukannya. Namun karena perkembangan teknologi yang makin pesat, pemikiran akan pemindahan organ tubuh antar tubuh manusia dilakukan seiring dengan didukungnya fasilitas yang ada.

Pemindahan organ tubuh manusia antar tubuh ini pada dasarnya dapat dilakukan dan faktanya telah banyak orang yang telah berhasil melakukannya, namun apabila dikaji berdasarkan hukum Islam apakah pemindahan organ tubuh ini atau yang lebih dikenal dengan donor anggota tubuh (transplantasi) halal dilakukan?

Antara kebutuhan yang mendesak secara kesehatan atau menjalankan ibadah, donor organ tubuh manusia menjadi permasalahan ketika banyak pendapat yang menyebutkan bahwa tindakan tersebut haram dilakukan karena didasari dari keraguan yang tidak pernah dicontohkan oleh Nabi Muhammad SAW. Apabila alasan ini digunakan maka banyak hal di bidang kesehatan yang sebelumnya tidak pernah ada di zaman nabi. Dan apabila pemikiran ini tetap dipertahankan, maka Islam adalah agama penghambat perkembangan dalam ilmu pengetahuan.

Bahwa alasan di atas tidak dapat dijadikan rujukan karena sejatinya Islam yang sangat mendukung pekembangan atas ilmu pengetahuan. Sejarahnya pun banyak umat Islam yang berkembang dan orang-orang dari wilayah barat banyak yang belajar pada para Muslim dahulunya. Donor anggota tubuh yang dikenal dalam dunia kedokteran adalah transplantasi telah berkembang hingga saat ini, dan faktanya banyak orang yang telah berhasil melakukannya. Dan tidak dapat dipungkiri bahwa donor organ tubuh ini akan menjadi suatu kebutuhan bagi beberapa orang ketika hanya donor organ tubuh yang dapat dilakukan ketika suatu pilihan datang kepadanya, antara hidup atau mati. Dengan kata lain ketika seseorang membutuhkan donor organ tubuh dari orang lain, maka mau tidak mau mendapatkan donor organ tubuh dari orang lain harus dilakukan. Atau sebaliknya melakukan donor organ tubuh kepada orang lain dapat dilakukan ketika orang tersebut memang benar ingin melakukannya.

Islam adalah agama yang tidak pernah menghambat di bidang ilmu pengetahuan khususnya kesehatan namun atas beberapa permasalahan berupa pertanyaan seperti: bolehkan seseorang berwasiat untuk mendonorkan anggota tubuhnya? atau keluarga (ahli waris) mendonorkan atau memberi izin kepada dokter untuk mengambil organ tubuh untuk didonorkan, apakah perbuatan ini termasuk kategori ibadah, muamalah atau jinayat, apakah anggota tubuh dianggap sebagai "barang" sehingga boleh dimiliki atau "bukan barang" 


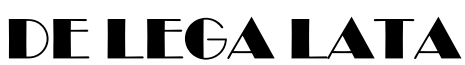

Jurnal Ilmu Hukum

FAKULTAS HUKUM UMSU
Donor Anggota Tubuh...(Rasta Kurniawati Br. Pinem ) Volume 5 Nomor 1, Januari - Juni 2020, 67-78 DOI: https://doi.org/10.30596/dll.v5i1.3449

sehingga tidak sah dimiliki, apakah pengambilan anggota tubuh oleh dokter harus dengan izin si donor (atau keluarganya), atau dokter boleh mengambil anggota tubuh orang yang telah meninggal dunia tanpa izin dan bebas mencangkoknya kepada orang lain yang memerlukan. Berikut ini akan dipapaparkan hal-hal yang menjadi permasalahan di atas didasari dengan kajian ushul fiqh.

Hukum Islam merupakan seperangkat aturan yang ditetapkan oleh Allah SWT untuk kemaslahatan manusia di dunia dan di akhirat. Hukum Islam tersebut bersumber pada al-Quran dan as-Sunnah kemudian dapat dipahami sehingga dapat dipedomani dalam bidang ibadah maupun muamalah. Seiring dengan hal tersebut di atas bahwa perkembangan zaman, waktu dan ilmu pengetahuan serta teknologi yang ikut mewarnai perkembangan manusia, yang juga menimbulkan permasalahan-permasalahan baru yang harus segera mendapatkan jawabanjawaban baru sebagai dasar praktik kepastian hukum karena umat Islam selalu terikat dan wajib terikat dengan hukum Islam tersebut.

\section{METODE PENELITIAN}

Sesuai dengan permasalahan yang diteliti, penelitian ini merupakan penelitian hukum (legal research). Istanto, mengatakan penelitian hukum adalah penelitian yang diterapkan atau diberlakukan khusus pada ilmu hukum (Istanto, 2007, h. 29). Sejalan dengan Istanto, Marzuki mengatakan penelitian hukum adalah suatu proses untuk menemukan aturan hukum, prinsipprinsip hukum, maupun doktrin-doktrin hukum guna menjawab isu-isu hukum yang dihadapi (Marzuki, 2005 h. 35). Penelitian hukum atau penelitian normatif adalah penelitian yang datanya bersumber dari data sekunder (Erwin Asmadi, 2019, h. 104-105). Jenis penelitian yang digunakan dalam penulisan ini adalah penelitian pustaka (library research). Library research berarti penelitian yang menggunakan dokumen tertulis sebagai data, dan sumber data yang digunakan dalam penelitian ini mencakup bahan hukum primer, bahan hukum sekunder dan bahan tersier. Bahan hukum primer adalah bahan hukum yang mengikat atau yang membuat orang taat hukum, meliputi produk hukum yang menjadi bahan kajian dan produk hukum sebagai alat kritiknya. Bahan hukum sekunder meliputi penjelasan bahan hukum primer berupa doktrin para ahli yang ditemukan dalam buku, jurnal, dan dalam website. Spefisikasi penelitian dalam penulisan ini berupa penelitian deskriptif analisis. Deskriptif adalah menunjukkan komparasi atau hubungan separangkat data dengan seperangkat data yang lain (Zainuddin, 2019, h. 273).

\section{PEMBAHASAN DAN ANALISIS}

\section{Pengertian dan Tujuan Transplantasi Organ Tubuh}

“Transplantasi” berasal dari bahasa Inggris yaitu transplant yang berarti move (a body organ ...) from one person or part of body to another (memindahkan sebagian dari organ tubuh dari seseorang atau dari tubuh sendiri ke tempat lain (Oxfort Leaner's Pocket Dictionary, 1991, h. 442). Sedangkan dalam kamus Kontemporer English Indonesia, trasnplantation berarti, pemindahan, bentuk kata kerja dari kata transplant yang berarti memindahkan bagian tubuh ke orang lain atau binatang (Peter Salim, 2012: h. 5). 
DE LEGA LATA

Jurnal Ilmu Hukum

FAKULTAS HUKUM UMSU
Donor Anggota Tubuh...(Rasta Kurniawati Br. Pinem ) Volume 5 Nomor 1, Januari - Juni 2020, 67-78 DOI: https://doi.org/10.30596/dll.v5i1.3449

Transplantasi maksudnya adalah pemindahan suatu jaringan atau organ manusia tertentu dari tempat lain pada tubuhnya sendiri atau tubuh orang lain dengan persyaratan dan kondisi tertentu. Sedangkan menurut ilmu kedokteran transplantasi ialah pemindahan jaringan atau organ tubunh dari suatu tempat ke tempat lain (Barid Ishom, 1979: h. 8). Adapun yang dimaksud dengan organ adalah kumpulan jaringan yang mempunyai fungsi yang berbeda sehingga merupakan satu kesatuan yang mempunyai fungsi tertentu seperti jantung dan hati.

Sedangkan transplantasi dalam literatur Arab Kontemporer dikenal dengan istilah naqad al-a'da' atau juga disebut al-wasl (penyambungan). Secara rinci transplantasi dapat dilihat dari istilah kedokteran. Sedangkan transplantasi dalam istilah bahasa Indonesia lebih dikenal dengan "pencangkokan".

Adapun tujuan transplantasi organ tubuh adalah untuk kemanusiaan saja. Transplantasi organ, jaringan dan sel tubuh merupakan usaha mulia dalam upaya menyehatkan dan mensejahterakan manusia. Transplantasi organ dan atau jaringan tubuh manusia merupakan tindakan medik yang sangat bermanfaat bagi pasien dengan gangguan fungsi organ tubuh yang berat. Hal ini sebagai terapi pengganti (alternatif) yang merupakan upaya terbaik untuk menolong pasien dengan kegagalan organnya, karena hasilnya lebih memuaskan. Transplantasi sebagai upaya untuk melepaskan manusia dari penderitaan yang secara biologis mengalami keabnormalan, atau menderita suatu penyakit yang mengakibatkan rusaknya fungsi suatu organ, jaringan atau sel. Hal ini tentunya bertujuan:

1. Kesembuhan dari suatu penyakit, misalnya kebutuhan rusaknya jantung, ginjal dan sebagainya.

2. Pemulihan kembali fungsi dam organ, jaringan atau sel yang telah rusak atau mengalami kelainan tapi sama sekali tidak terjadi kesakitan biologis misalnya bibir sumbing (Chuzaimah dan Hafizh Anshary, 1995, h. 65).

Maka transplantasi merupakan pemindahan jaringan atau organ tubuh dari satu tempat ke tempat lainnya. Hal ini dapat dilakukan pada satu individu atau dua individu.

\section{Dalil-Dalil Yang Digunakan Transplantasi Organ Tubuh (Fatwa MUI)}

Penetapan dibolehkannya transplantasi (donor anggota tubuh) Fatwa Majelis Ulama Indonesia Tahun 2009 di Padang Panjang adalah:

1. Al-Quran

a. QS. al-Maidah: 2 yang artinya: Dan tolong-menolonglah kamu dalam (mengerjakan) kebajikan dan takwa, dan jangan tolong-menolong dalam berbuat dosa dan pelanggaran. dan bertakwalah kamu kepada Allah, Sesungguhnya Allah Amat berat siksa-Nya (Indra Laksana, dkk, 2011, h. 106). Ayat tersebut menyuruh berbuat baik kepada sesama manusia dan tolong menolong dalam hal kebaikan. Termasuk didalamnya memberikan organ tubuh kepada orang yang memerlukan merupakan suatu perbuatan tolong menolong dalam kebaikan karena memberi manfaat bagi orang lain.

b. QS. al-Hasyr: 9 yang artinya: "Dan orang-orang yang telah menempati kota Madinah dan telah beriman (Anshor) sebelum (kedatangan) mereka (Muhajirin), mereka (Anshor) 
Jurnal Ilmu Hukum FAKULTAS HUKUM UMSU
Donor Anggota Tubuh...(Rasta Kurniawati Br. Pinem ) Volume 5 Nomor 1, Januari - Juni 2020, 67-78 DOI: https://doi.org/10.30596/dll.v5i1.3449

'mencintai' orang yang berhijrah kepada mereka (Muhajirin). dan mereka (Anshor) tiada menaruh keinginan dalam hati mereka terhadap apa-apa yang diberikan kepada mereka (Muhajirin); dan mereka mengutamakan (orang-orang muhajirin), atas diri mereka sendiri, Sekalipun mereka dalam kesusahan. dan siapa yang dipelihara dari kekikiran dirinya, mereka Itulah orang orang yang beruntung" (Indra Laksana, dkk, 2011, h. 546). Ayat di atas mengisyaratkan berupa anjuran untuk mengutamakan memelihara orang lain yang mengalami kesusahan atau kesulitan. Mendonorkan organ tubuh kepada orang lain yang membutuhkan, merupakan salah satu upaya menghilangkan kesusahan atau kesulitan yang dialami orang lain tersebuat.

c. QS. al-Isra': 70 yang artinya: "Dan Sesungguhnya telah Kami muliakan anak-anak Adam, Kami angkut mereka di daratan dan di lautan, Kami beri mereka rezki dari yang baik-baik dan Kami lebihkan mereka dengan kelebihan yang sempurna atas kebanyakan makhluk yang telah Kami ciptakan” (Indra Laksana, dkk, 2011, h. 289). Ayat di atas menjelaskan bahwa manusia merupakan makhluk yang dihormati dan dimuliakan Allah SWT. Kemuliaan yang diberikan oleh Allah ini tidak berakhir dengan pisahnya nyawa dari badan, walaupun jenazah juga tetap harus dihormati. Pada dasarnya transplantasi dilarang oleh agama Islam karena agama Islam memuliakan manusia baik masih hidup atau pun sudah mati. Sebagaimana Albaqarah ayat 195 yang artinya: "Dan belanjakanlah (harta bendamu) di jalan Allah, dan janganlah kamu menjatuhkan dirimu sendiri ke dalam kebinasaan, dan berbuat baiklah, karena Sesungguhnya Allah menyukai orang-orang yang berbuat baik." (Indra Laksana, dkk, 2011, h. 30). Maksud ayat di atas yaitu, Islam tidak membenarkan seseorang melakukan tindakan yang dapat membawa kerusakan dirinya. Oleh sebab itu, tidak diperkenankan seseorang mendonorkan organ tubuh sehingga menimbulkan dharar (bahaya) bagi dirinya.

2. Al-Hadist

Di samping ayat-ayat al- Qur'an, Ijtima Ulama Komisi Fatwa se Indonesia III tahun 2009 di Padang Panjang mendasarkan keputusannya kepada beberapa hadis, yaitu :

Hadis Riwayat Muslim

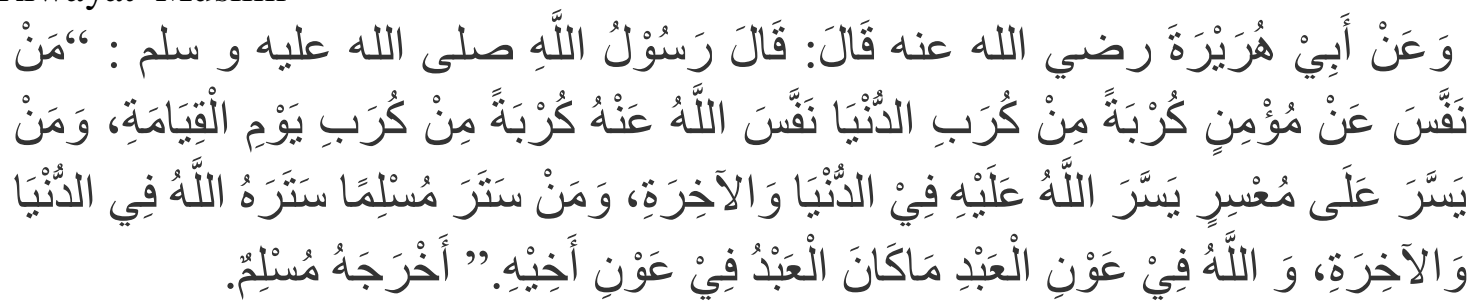

Artinya: "Dari Abi Hurairah ra. Ia berkata: "Rasulullah SAW bersabda: Barang siapa yang melapangkan orang mukmin dari kesempitan urusan dunia niscaya Allah akan melapangkan kesempitannya di hari kiamat. Barang siapa memudahkan kesulitan orang mukmin niscaya Allah akan memudahkan kesulitannya di dunia dan akhirat. Barang siapa menutupi kekurangan orang muslim niscaya Allah akan menutupi kekurangannya di dunia dan akherat. Allah akan menolong hamba-Nya sepanjang hamba tersebut menolong (Al-Imam Abi Al-Husain Muslim bin Al-Hajjaj Al -Qusyairi Al-Yasaburi, dkk, h. 602). Hadits tersebut berisikan anjuran untuk menolong orang lain yang dalam kesulitan. Seseorang yang buta tidak bisa melihat, maka tolong 
Jurnal Ilmu Hukum

FAKULTAS HUKUM UMSU
Donor Anggota Tubuh...(Rasta Kurniawati Br. Pinem ) Volume 5 Nomor 1, Januari - Juni 2020, 67-78 DOI: https://doi.org/10.30596/dll.v5i1.3449

agar dapat terhindar dari kesulitan yang dialaminya.

Hadist Nabi SAW yang diriwayatkan Imam Ahmad Ashab Sunan dan Turmuzi :

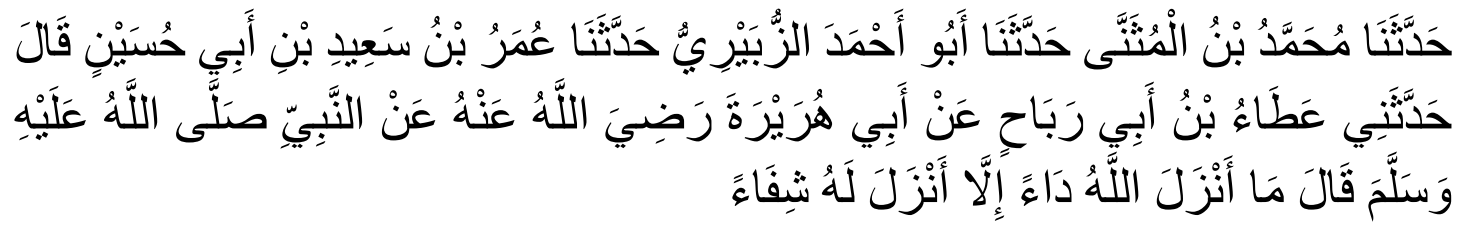

Artinya: "Berobatlah karena Allah SWT tidak menurunkan penyakit kecuali menyertainya dengan menurunkan obatnya di luar satu penyakit yaitu pikun” (Abi Isa Muhammad bin Isa bin Saurah at-Turmuzi, Sunan at-Turmudzi, tt., h). Hadist tersebut menunjukkan, bahwa wajib berobat jika sakit, apapun jenis dan macam penyakitnya, kecuali penyakit tua. Oleh sebab itu, melakukan transplantasi dalam upaya untuk menghilangkan penyakit hukumnya mubah, asalkan tidak melanggar norma ajaran Islam.

Hadist riwayat Imam Nasai, Ibn Majah dan Hakim yang artinya: ”Sesungguhnya Allah SWT tidak akan menurunkan penyakit kecuali menyertainya dengan menurunkan (obat) untuk kesembuhan, maka berobatlah" (Abi Abdillah Muhammad Ibn Yazid al-Qazwini, Sunan Ibn Majah, h. 1138). Dalam Hadits ini Rasulullah menyatakan bahwa penyakit ada obatnya, apabila obat itu tepat, maka penyakit itu akan sembuh atas izin Allah.

\section{Kaidah Fiqhiah dalam Donor Anggota Tubuh}

Kaedah Fiqhiah :

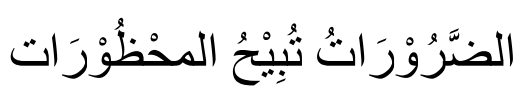

"Darurat membolehkan sesuatu yang dilarang" (Syeikh Abu Bakar, Al-Faraidul Bahiyyah, Terj. Moh. Adib, Al-Faraidul Bahiyyah, 1977: h. 21). Pada prinsipnya hukum pokok transplantasi adalah dilarang. Akan tetapi, apabila untuk menolong orang lain dan tidak diperoleh upaya medis lain untuk menyembuhkannya (darurat), maka ketentuan hukum yang prinsip itu dapat berubah.

Kaidah Fiqhiah yang artinya: "Kehormatan orang yang hidup lebih agung dari pada kehormatan orang yang telah mati” (Muhammad Syarbini Al-Khathib, dkk, h. 307).

Kaidah Fiqhiah:

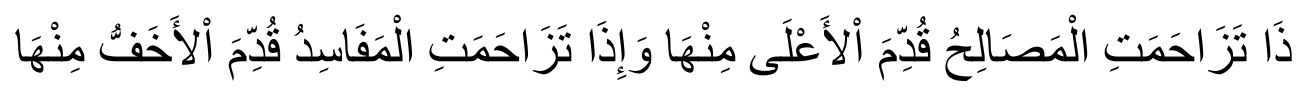

Artinya: "Apabila dua kerusakan atau dua bahaya saling bertentangan, maka dijaga bahaya yang lebih besar dengan jalan melaksanakan perbuatan yang mengandung bahaya lebih kecil" Kaidah Fiqhiah :

$$
\text { وضدُّه تز احٌُ المفاسدِ فازْتَكِب الأدنى من المفاس }
$$

Artinya: "Apabila dua keburukan atau dua bahaya saling bertentangan, maka syara' memilih untuk menolak bahaya yang lebih parah dan keburukan yang lebih besar" (Syeikh Abu Bakar, Al-Faraidul Bahiyyah, Terj. Moh. Adib, Al-Faraidul Bahiyyah, 1977, h. 24). Maksud kaidah di atas adalah seseorang tidak boleh mengorbankan dirinya untuk 
DE LEGA LATA

Jurnal Ilmu Hukum

FAKULTAS HUKUM UMSU
Donor Anggota Tubuh...(Rasta Kurniawati Br. Pinem ) Volume 5 Nomor 1, Januari - Juni 2020, 67-78 DOI: https://doi.org/10.30596/dll.v5i1.3449

menyelamatkan orang sakit dari kematian yang menyebabkan dirinya dalam bahaya. Maksudnya memilih satu nyawa untuk diselamatkan adalah pilihan terkecil ketimbang dua nyawa harus melayang bersamaan.

Kaidah Fiqhiah:

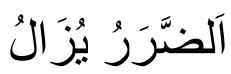

Artinya: "Bahaya harus dihilangkan" (Syeikh Abu Bakar, Al-Faraidul Bahiyyah, Terj. Moh. Adib, Al-Faraidul Bahiyyah, 1977, h. 1). Menurut kaidah hukum di tersebut, bahaya harus ditanggulangi dengan usaha pengobatan. Dan jika usaha pengobatan secara medis biasa tidak bisa menolong jiwanya, maka demi menyelamatkan jiwa, transplantasi diperbolehkan karena keadaan darurat.

Kaidah Fiqhiah yang artinya: "Ridlo atas sesuatu berarti juga ridlo atas apa yang terlahir darinya" (Syeikh Abu Bakar, Al-Faraidul Bahiyyah, Terj. Moh. Adib, Al-Faraidul Bahiyyah, 1977, h. 49). Maksud kaidah ini, mengecualikan tindakan-tindakan yang disyaratkan akibatnya tidak akan membahayakan. Maka, tidaklah terlarang seseorang mewasiatkan organ tubuh kepada orang lain setelah meninggal dunia. Sebab yang demikian itu akan memberikan manfaat yang utuh kepada orang lain tanpa menimbulkan mudharat (kemelaratan atau kesengsaraan) sedikit pun kepada dirinya.

\section{Kaidah Ushul Fikih}

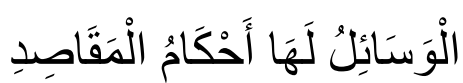

Artinya: "Sarana memiliki hukum sebagaimana hukum maksud" (Syeikh Abu Bakar, AlFaraidul Bahiyyah, Terj. Moh. Adib, Al-Faraidul Bahiyyah, 1977: h. 49). Maksud kaidah di atas adalah penetapan hukum memiliki status hukum yang sama dengan obyek hukum itu sendiri. Maka hukum transplantasi organ lain dan donor anggota tubuh karena memiliki obyek yang sama maka maksud yang sama (Djamaluddin Miri, Ahkamul Fuqaha, 2007: h. 286).

\section{Maslahah Mursalah}

Pembentukan hukum itu tidak dimaksudkan, kecuali merealisasikan kemaslahatan umat manusia, artinya mendatangkan keuntungan bagi manusia dan menolak mudharat serta menghilangkan kesulitan dari padanya. Sebagai contoh : Pelaksanaan wasiat donor kornea mata merupakan salah satu perbuatan untuk merealisasikan kemaslahatan orang yang hidup. Bahkan dalam Fatwa MUI tanggal 13 Juni 1979 yang menyebutkan bahwa seseorang yang berwasiat akan mendonorkan kornea matanya setelah meninggal dengan disetujui dan disaksikan ahli warisnya, wasiat itu dapat dilaksanakan dan harus dilakukan oleh ahli bedah. Dalam fatwa MUI ini dapat dipahami bahwa pencangkokan kornea mata diperbolehkan dengan syarat-syarat sebagai berikut : 1). Donor adalah orang yang telah meninggal, 2). Ada wasiat dari donor yang diketahui, disaksikan, dan disetujui oleh ahli waris, 3). Pengambilan kornea mata dilakukan oleh ahli bedah yang berpengalaman. 
DE LEGA LATA

Jurnal Ilmu Hukum

FAKULTAS HUKUM UMSU
Donor Anggota Tubuh...(Rasta Kurniawati Br. Pinem ) Volume 5 Nomor 1, Januari - Juni 2020, 67-78 DOI: https://doi.org/10.30596/dll.v5i1.3449

\section{Pendapat Ulama Tentang Transplantasi Organ Tubuh}

Transplantasi organ tubuh menurut Al-Qardhawi adalah bahwa seorang muslim diperbolehkan mendonorkan organ tubuhnya ketika ia masih hidup meskipun ada yang mengatakan bahwa diperbolehkannya seseorang mendonorkan sesuatu ialah apabila itu miliknya. Namun, Al-Qardhawi, berpendapat bahwa meskipun tubuh merupakan titipan dari Allah, manusia diberi wewenang untuk memanfaatkannya dengan mempergunakanya, sebagai harta. Harta pada hakikatnya milik Allah sesuai dengan firman Allah yang artinya: "Dan berikanlah kepada mereka sebahagian dari harta Allah yang dikaruniakan-Nya kepadamu" (QS. An-Nur : 33)

Walaupun Allah SWT. memberi wewenang kepada manusia untuk memilikinya dan membelanjakan harta itu. Sebagaimana manusia boleh mendermakan sebagian hartanya untuk kemaslahatan orang lain yang membutuhkannya maka diperkenankan juga seseorang mendonorkan sebagian tubuhnya untuk orang lain yang memerlukannya (Yusuf Al-Qardhawi, Fatwa Al-Mu'asirah, 1994, h. 532).

Lebih lanjut Al-Qardhawi menjelaskan perbedaan keduanya dengan mengatakan bahwa manusia adakalanya boleh membelanjakan seluruh hartanya. Akan tetapi, dia tidak boleh mendermakan seluruh anggota badannya, bahkan dia tidak boleh mendermakan dirinya (mengorbankan dirinya) untuk menyelamatkan orang sakit dari kematian, dari penderitaan yang sangat atau dari kehidupan yang sengsara. Dalam kaidah syara' ditetapkan bahwa "bahaya itu harus dihilangkan sedapat mungkin". Karena itulah disyariatkan untuk menolong orang yang dalam keadaan terluka, memberi makan orang kelaparan, melepaskan tawanan, mengobati orang yang sakit dan menyelamatkan orang yang sedang dalam bahaya baik mengenai jiwanya maupun lainnya. Tidak diperkenankan seorang muslim yang melihat dharar (bahaya, bencana) yang menimpa seseorang atau sekelompok orang, tetapi dia tidak berusaha menghilangkan bahaya itu, padahal dia mampu menghilangkan bahaya itu, padahal ia mampu menghilangkannya atau tidak berusaha menghilangkannya menurut kemampuannya (Yusuf AlQardhawi, Fatwa Al-Mu'asirah, 1994, h. 532). Berdasarkan hal ini Al-Qradhawi ingin berusaha menghilangkan penderitaan Muslim yang menderita gagal ginjal, misalnya dengan mendonorkan salah satu gunjalnya yang sehat, maka tindakan demikian dibenarkan syara' bahkan terpuji dan berpahala (Badri Khaeruman, 2010, h. 217).

Kebolehan mendonorkan sebagian organ tubuh tidak bersifat mutlak, tetapi muqayyad. Artinya, kebolehan itu dengan beberapa persyaratan. Di antaranya syaratnya adalah:

1. Tidak boleh mendonorkan sebagian organ tubuh yang justru akan menimbulkan dharar (bahaya) dan kesengsaraan bagi dirinya atau bagi seseorang yang mempunyai hak tetap atas dirinya.

2. Tidak diperkenankan seseorang mendonorkan organ tubuh yang hanya satu-satunya dalam tubuhnya, misalnya hati atau jantung, karena tidak mungkin dapat hidup tanpa adanya organ tubuh tersebut dan tidak diperkenankan menghilangkan dharar dari orang lain dengan menimbulkan dharar pada dirinya. Adanya kaidah : "Bahaya itu harus dihilangkan" 
DE LEGA LATA

Jurnal Ilmu Hukum

FAKULTAS HUKUM UMSU
Donor Anggota Tubuh...(Rasta Kurniawati Br. Pinem ) Volume 5 Nomor 1, Januari - Juni 2020, 67-78 DOI: https://doi.org/10.30596/dll.v5i1.3449

dibatasi oleh kaidah : "bahaya itu tidak boleh dihilangkan dengan menimbulkan bahaya pula”. (Yusuf Al-Qardhawi, Fatwa Al-Mu'asirah, h. 533).

Persyaratan lainnya yang perlu diperhatikan dalam kebolehan mendonorkan organ tubuh adalah hanya boleh dilakukan oleh orang yang telah dewasa dan berakal sehat. Sedangkan anak kecil tidak dibolehkan mendonorkan organ tubuhnya karena ia tidak tahu persis kepentingan dirinya. Begitu pula, seorang wali tidak boleh mendonorkan organ tubuh anak kecil dan orang gila yang di bawah perwaliannya, disebabkan keduanya tidak mengerti. Mengenai mewasiatkan organ tubuh setelah meninggal dunia Al-Qardhawi memperbolehkanya. Sebab, yang demikian itu akan memberikan manfaat yang utuh kepada orang lain tanpa menimbulkan kesengsaraan sedikitpun kepada dirinya karena organ tubuh orang yang meninggal akan lepas berantakan dan dimakan tanah beberapa hari setelah dikubur. Apabila ia berwasiat untuk mendermakan organ tubuhnya itu dengan niat mendekatkan diri dan mencari keridaan Allah, ia akan mendapatkan pahala sesuai dengan niat dan amalnya. Alasan Al-Qardhawi adalah dalam hal ini tidak ada satupun dalil syara yang mengharamkannya, sedangkan "hukum asal segala sesuatu adalah mubah, kecuali jika ada dalil yang sahih yang jelas melarangnya".

Adapun hadis Nabi SAW. :

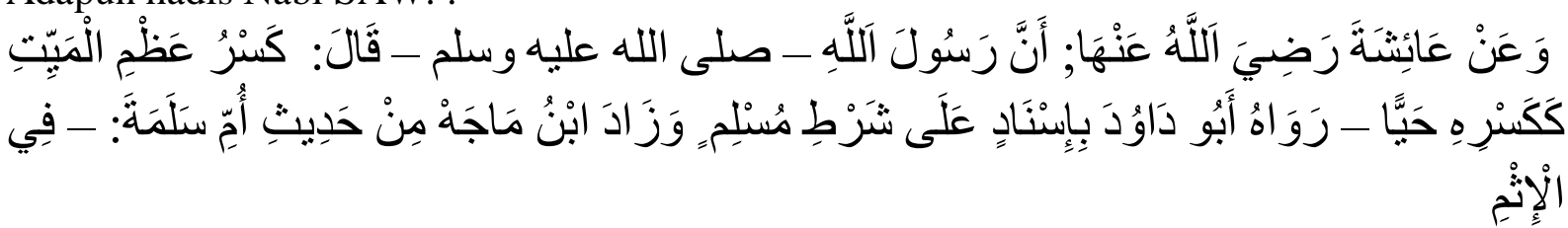

"Mematahkan tulang mayat itu seperti mematahkan tulang orang yang hidup" (HR.Abu Daud) (Abu Daud, Sunan Abu Daud, dkk, h. 212). Al-Qardhawi berpendapat bahwa hadis tersebut hanya membicarakan masalah mematahkan tulang mayat, padahal pengambilan organ tubuh tidak mengenai tulang. Larangan yang dimaksud hadis tersebut di atas adalah larangan memotong-motong tubuh mayat, merusaknya, dan mengabaikannya sebagaimana yang dilakukan kaum Jahiliyah dalam peperangan. Hal itu yang dilarang dan tidak diridhai dalam Islam. Namun jika dengan cara wasiat organ tubuh mayat boleh didonorkan, tetapi dengan syarat : yaitu tidak boleh mendermakan atau mendonorkan seluruh tubuh, atau sebagian besar organ tubuh, sehingga meniadakan hukum-hukum mayat bagi yang bersangkutan, seperti tentang kewajiban memandikan, mengkafani, menshalatkan dan menguburkannya (Yusuf AlQardhawi, Fatwa Al-Mu'asirah, h. 536).

Terkait tentang ahli waris atau wali yang mendonorkan sebagian organ tubuh mayat tanpa ada wasiat dari si mayat, tidak dilarang bagi ahli waris menonorkan sebagian organ tubuh mayat yang dibutuhkan oleh orang-orang sakit untuk mengobati mereka, seperti ginjal, jantung dan sebagainya dengan niat sedekah dari si mayat. Hal ini merupakan sedekah yang pahalanya berkesinambungan selama si sakit masih memanfaatkan oragn yang didonorkan. Alasannya adalah apabila seseorang sudah meninggal dunia, ia dianggap tidak layak memiliki sesuatu. Sebagaimana kepemilikan harta yang juga berpindah kepada ahli warisnya maka mungkin dapat dikatakan bahwa si mayat menjadi hak wali atau warisnya. Meskipun demikian jika 
DEIEGA LATA

Jurnal Ilmu Hukum

FAKULTAS HUKUM UMSU
Donor Anggota Tubuh...(Rasta Kurniawati Br. Pinem ) Volume 5 Nomor 1, Januari - Juni 2020, 67-78 DOI: https://doi.org/10.30596/dll.v5i1.3449

memang si mayat berwasiat/pesan ketika dia masih agar tidak mendonorkan organ tubuhnya, maka hal ini tidak diperbolehkan (Yusuf Al-Qardhawi, Fatwa Al-Mu'asirah, h. 536).

Dari beberapa penjelasan di atas terkait transplantasi organ tubuh jika dikaitkan dengan konsep maslahah yang terkandung di dalamnya, maka dapat dipahami, bahwa jika ditinjau dari dari segi maslahah, dalam pandangan syara' bahwa dapat menggunakan maslahah murslahah dalam hukum transplantasi tersebut. Hal ini dilakukan karena hukum persolan transplantasi tidak ditemukan dalam ketentuan nash syariat, baik memperbolehkannya maupun melarangnya. Bahwa segala hukum yang ditetapkan harus sesuai maksud syariat dan memperhatikan kemaslahatan manusia maka ditempuh dengan cara maslahah mursalah. Sepanjang kemaslahatan yang diperoleh lebih besar dan tidak membahayakan orang yang menerima (resipien) dan pemberi donor maka transplantasi boleh dilakukan. Tentunya dengan beberapa syarat bahwa yang didonorkan itu bukan organ tubuh satu-satunya, seperti hati, otak, atau jantung. Organ tubuh bagian luar, seperti mata, tangan, kaki, dan organ tubuh bagian dalam yang berpasangan, tetapi salah satu dari pasangan itu tidak berfungsi atau sakit (karena dianggap satu organ). Hal ini dilarang karena akan menimbulkan bahaya yang lain, padahal ada kaidah mengatakan : "Bahaya (dharar) itu tidak boleh dihilangkan dengan menimbulkan bahaya (dharar) yang lain (Yusuf Al-Qardhawi, Fatwa Al-Mu'asirah, h.539).

\section{KESIMPULAN}

Bahwa transplantasi organ tubuh diperbolehkan apabila organ tubuh tersebut itu miliknya sendiri, karena meskipun tubuh merupakan titipan dari Allah, manusia diberi wewenang untuk memanfaatkannya dengan mempergunakanya, sebagai harta. Maka Allah SWT. memberi wewenang kepada manusia untuk memilikinya dan membelanjakan harta itu. Sebagaimana manusia boleh mendermakan sebagian hartanya untuk kemaslahatan orang lain yang membutuhkannya maka diperkenankan juga seseorang mendonorkan sebagian tubuhnya untuk orang lain yang memerlukannya. Dari hal tersebut bahwa dibolehkannya transplantasi organ tubuh dari metode ta'liliah, bahwa organ tubuh dipersamakan sengan harta yang diberikan kepada manusia, maka pemberlakuan transplantasi organ tubuh dipersamakan dengan bagaimana kaidah pengelolaan harta. Transplantasi organ tubuh menggunakan metode maslahah murslahah. Hal ini dilakukan karena hukum persoalan transplantasi tidak ditemukan dalam ketentuan nash syariat, baik memperbolehkannya maupun melarangnya. Atas dasar bahwa segala hukum yang ditetapkan harus sesuai maksud syariat dan memperhatikan kemaslahatan manusia maka ditempuh dengan cara maslahah mursalah. Sepanjang kemaslahatan yang diperoleh lebih besar dan tidak membahayakan orang yang menerima (resipien) dan pemberi donor maka transplantasi boleh dilakukan. Tentunya dengan beberapa syarat bahwa yang didonorkan itu bukan organ tubuh satu-satunya, sperti hati, otak, atau jantung., organ tubuh bagian luar,, seperti mata, tangan, kaki, dan organ tubuh bagian dalam yang berpasangan, tetapi salah satu dari pasangan itu tidak berfungsi atau sakit (karena dianggap satu organ). 
DE IEGA LATA

Jurnal Ilmu Hukum

FAKULTAS HUKUM UMSU
Donor Anggota Tubuh...(Rasta Kurniawati Br. Pinem ) Volume 5 Nomor 1, Januari - Juni 2020, 67-78 DOI: https://doi.org/10.30596/dll.v5i1.3449

\section{SARAN}

Bahwa perkembangan zaman akan menjadi malapetaka ketika manusia tidak mampu mengikutinya bahkan bertahan atasnya. Perkembangan zaman akan terus menuntut manusia untuk selalu melakukan perubahan demi adanya keseimbangan antara cara manusia memenuhi kebutuhannya dengan adanya perubahan waktu yang terus terjadi. Donor organ tubuh manusia adalah sebagai bentuk dari manusia atas cara pemenuhan kebutuhan hidupnya. Melakukan donor organ tubuh memang tidak dapat dikatakan untuk memenuhi kebutuhan manusia namun bagaimana seseorang melakukan pemenuhan atas kebutuhan hidup orang lain. Donor organ tubuh manusia berdasarkan hukum Islam sama sekali tidak ada larangan atasnya namun kebolehan tersebut bersifat kondisional. Sifat kondisional ini harus dapat diketahui oleh seluruh umat Muslim sehingga tidak ada lagi kegiatan donor organ tubuh yang dilakukan secara tidak manusiawi, sehingga tindakan donor organ tubuh manusia tersebut dapat dikategorikan melaksanakan ibadah ketika niatnya hanya untuk Allah SWT. 
Jurnal Ilmu Hukum

FAKULTAS HUKUM UMSU
Donor Anggota Tubuh...(Rasta Kurniawati Br. Pinem ) Volume 5 Nomor 1, Januari - Juni 2020, 67-78 DOI: https://doi.org/10.30596/dll.v5i1.3449

\section{DARTAR PUSTAKA}

Abi Abdil Syeikh Abu Bakar, Al-Faraidul Bahiyyah, Terj. Moh. Adib, Al-Faraidul Bahiyyah. (1977). Kudus : Menara Kudus

Abi Isa Muhammad bin Isa bin Saurah at-Turmuzi, Sunan at-Turmudzi. Bairut : Dar al-Kutub al-Ilmiyyah

Abu Daud, Sunan Abu Daud, Tahqiq Muhammad Muhyi Ad-Din abd Al-Hamid. Jilid 3. Bairut

Al-Imam Abi Al-Husain Muslim bin Al-Hajjaj Al -Qusyairi Al-Yasaburi, Shahih Muslim,

Juz II, (Beirut: Dar al-Kutub al-Ilmiyyah)

Al-Qardhawi, Yusuf. (1994). Fatwa Al-Mu'asirah, jilid 2. Kuwait: Dar Al-Qalam

Asmadi, Erwin. (2019). Regulasi Mandiri Transportasi Online Dalam Pembayaran Pesanan Makanan Atas Konsumen Yang Ingkar Janji, 4, (1), 103-118. https://doi.org/10.30596/dll.v4i1.3164.

Badri Khaeruman. (2010). Hukum Islam dalam Perubahan Sosial. Bandung: Pustaka Setia

Barid Ishom. (1979). Dasar Pengertian Transplantasi. (Ceramah di Hadapan Sidang Majelis Tarjih Muhammadiyah, 1979)

Chuzaimah, Hafizh Anshary. (1995). Problematika Hukum Islam Kontemporer. Jakarta : Pustaka

Indra Laksana, dkk. (2011). Al-Qur'an dan Terjemah Dilengkapi dengan Kajian Usul Fiqih. Bandung: Syamil Qur'an

Miri, Djamaluddin. (2007). Ahkamul Fuqaha; Solusi Problematika Aktual Hukum Islam, Keputusan Muktamar, Munas dan Konbes Nahdlatul Ulama (1926-2004 M), cetakan ke-3. Surabaya: Lajnah Ta'lif Wan Nasyr (LTN) NU Jawa Timur

Muhammad Ibn Yazid al-Qazwini, Sunan Ibn Majah, Juz II. Bairut: Dar al-Fikr

Muhammad Syarbini Al-Khathib, Mughni Al-Muhtaj, Juz IV

Oxfort Leaner's Pocket Dictionary. (1991). Oxfort University Press

Salim, Peter. (2012). The Contemporary English-Indonesia Dictionary, Cet. Ke-5. Jakarta : Modern English Press

Zainuddin. (2019). Eksekusi Terhadap Pembatalan Surat Izin Mendirikan Bangunan Pada Perkara Tata Usaha Negara, 4, (2), 271-287. 